\title{
Analysis of Coexistence of DRM Plus and FM Broadcasting Systems
}

\author{
Karel ULOVEC \\ Dept. of Radio Engineering, Czech Technical University in Prague, Technicka 2, 166 27, Prague, Czech Republic \\ xulovec@fel.cvut.cz
}

\begin{abstract}
This paper deals with DRM (Digital Radio Mondiale) Plus and FM (Frequency Modulation) radio broadcasting systems coexistence. It brings results based on measurement of mutual interferences of each to other. Minimal necessary value of the signal to interference power ratio is measured under the given reception criteria. Results are useful for broadcasting networks planning. Different DRM Plus modes (i.e. combinations of various protection levels and data carriers modulations) are assumed in the case of DRM Plus reception interfered with by FM broadcasting. The differences for various modes are crucial for coverage design of DRM Plus system, while protection ratios have been recommended for only two of eight modes until now. Corrections of protection ratios for other modes are proposed in this paper. Different waveforms types of modulating signal for interfering FM signal are tested. The both mono and stereo FM mode and various sound quality criteria are considered in the case of FM broadcasting reception interfered with by DRM Plus. The influence of peak to average power ratio reduction of interfering DRM Plus signal is observed.
\end{abstract}

\section{Keywords}

Digital Radio Mondiale Plus (DRM+), FM radio broadcasting, coexistence, measurement, signal to interference power ratio, protection ratio

\section{Introduction}

Very high frequency (VHF) band II (from $87.5 \mathrm{MHz}$ to $108 \mathrm{MHz}$ ) is dedicated to terrestrial audio broadcasting. This band is extensively used for analog audio broadcasting using frequency modulation (FM). Many transmitted analog services can cause interferences during reception. It is problematic to find an assignment for a new service [1]. Digital audio broadcasting can bring more audio services together with high sound quality similarly as digital video broadcasting. Four digital terrestrial broadcasting systems are mentioned in [2] as candidates for the audio broadcasting digitization. In this paper, the Digital Radio Mondiale (DRM) Plus system is considered, which is suitable for broadcasting (not only) in VHF band II. But, introduction of any digital audio broadcasting system must be achieved with respect to existing analog services. Digital and analog audio broadcasting systems will probably coexist in VHF band II several years and they can cause mutual interferences of each to other [3].

This paper brings detailed analysis of DRM Plus and FM broadcasting systems coexistence based on measurement of mutual interferences. Different DRM Plus modes are assumed in the case of DRM Plus reception interfered with by FM broadcasting. The both mono and stereo FM mode and various sound quality criteria are considered in the case of FM broadcasting reception interfered with by DRM Plus. The rest of the paper is organized as follows. Section 2 deals with FM broadcasting and DRM Plus systems and with coexistence of these systems. Section 3 describes signal quality criteria, which are applied for measurement. Measurements of mutual interferences of DRM Plus and FM broadcasting are described and results are presented and discussed in Sec. 4. Section 5 concludes the paper.

\section{Broadcasting Systems}

Radio broadcasting system with frequency modulation (FM) is used for analog audio broadcasting (FM broadcasting) in VHF band II. Radio-frequency (RF) signal is modulated by audio-frequency (AF) signal with frequency in range from $30 \mathrm{~Hz}$ to $15 \mathrm{kHz}$. It is possible to transmit either one audio channel (mono mode) or two audio channels (stereo mode). Usually, two audio channels are transmitted by means of stereo coder placed before FM modulator in a transmitter and processed by stereo decoder placed after FM demodulator in a receiver. The maximal frequency of stereo coded AF signal is $53 \mathrm{kHz}$. FM broadcasting works with maximal frequency deviation of $75 \mathrm{kHz}$, thus bandwidth of RF modulated signal is about $250 \mathrm{kHz}$ [4]. To increase signal to noise power ratio (SNR), audio signal is processed by pre-emphasis filter in a transmitter and by de-emphasis filter in a receiver subsequently [4].

The Digital Radio Mondiale (DRM) Plus system $(\mathrm{DRM}+)$ can be employed for digital audio terrestrial broadcasting in VHF band II. The DRM standard, defined by [5], provides five robustness modes. Four robustness modes are dedicated for bands below $30 \mathrm{MHz}$ and one referred to as DRM+ is suitable for bands above $30 \mathrm{MHz}$. 
An effective source coding is applied for audio data bit rate reducing [6].

DRM system uses an orthogonal frequency division multiplexing (OFDM). This modulation format is based on data transmission via great number of carriers. Thus, spectrum of resulting OFDM signal has a flat shape with almost constant power spectral density, but sharply allocated by the first and last transmitted carriers. Carriers can be classified into three types - data, pilot and service description carriers. Thanks to parallel transmission on many carriers, symbol duration is prolonged. A useful part of symbol is extended further by so called guard interval to improve behavior in multi-path propagation conditions. Fractional part from the end of the symbol is repeated in the beginning. Table 1 shows values of important OFDM parameters for DRM+ system [2].

\begin{tabular}{|c|c|}
\hline Parameter & Value \\
\hline Useful part of symbol duration & $2.25 \mathrm{~ms}$ \\
\hline Guard interval duration & $0.25 \mathrm{~ms}$ \\
\hline Symbol duration & $2.5 \mathrm{~ms}$ \\
\hline Carrier spacing & $4444 / 9 \mathrm{~Hz}$ \\
\hline Number of carriers & 213 \\
\hline Occupied bandwidth & $951 / 9 \mathrm{kHz}$ \\
\hline
\end{tabular}

Tab. 1. Important parameters of OFDM for DRM+

DRM system conceptual scheme follows free logical channels. Audio data utilize main service channel (MSC). Data carriers of MSC are modulated by the same digital modulation. Either four-state phase shift keying (4PSK) or sixteen-state quadrature amplitude modulation (16QAM) can be chosen for DRM+. Higher number of modulation states leads to higher useful data bit rate of system but it introduces lower robustness against bit errors in the course of any disturbance. Robustness against bit errors is ensured by a multilevel forward error coding (FEC). Four protection levels (PL) are available with various code rates in MSC channel. Lower code rate means higher robustness of system but unfortunately lower useful data bit rate. The values of code rate and useful data bit rate and protection level numbering of DRM+ are summarized in Tab. 2 for the both data carriers modulation of MSC channel. Table 2 is arranged to point out, that the modes with the same protection level have different code rates for different modulations. While, the same code rate is, as example, for modes PL3 / 4PSK and PL2 / 16QAM.

\begin{tabular}{|c|c|c|c|c|}
\cline { 2 - 5 } \multicolumn{1}{c|}{} & \multicolumn{2}{c|}{ 4PSK } & \multicolumn{2}{c|}{ 16QAM } \\
\hline Code rate & PL & Bit rate (kbit/s) & PL & Bit rate (kbit/s) \\
\hline 0.25 & 0 & 37.3 & - & - \\
\hline $1 / 3$ & 1 & 49.7 & 0 & 99.4 \\
\hline 0.4 & 2 & 59.6 & - & - \\
\hline 0.411 & - & - & 1 & 122.4 \\
\hline 0.5 & 3 & 74.5 & 2 & 149.1 \\
\hline 0.625 & - & - & 3 & 186.4 \\
\hline
\end{tabular}

Tab. 2. Code rates, useful data bit rates and protection level (PL) numbering of DRM+ for 4PSK and 16QAM data carriers modulation of MSC channel.

Because of randomized data transmission on many carriers, resulting OFDM signal has high peak to average power ratio (PAPR). Linear amplifiers must be utilized to amplify signal with high PAPR. Thus, PAPR reduction might be desirable to decrease requirements for amplifiers. But, bit errors can increase during reception of DRM+ signal after PAPR reduction, as [7] illustrates in general. DRM+ signal after PAPR reduction has stronger shoulders in the spectrum out of useful signal band, what can cause higher interferences for relevant frequency offsets. On the other hand, reduced peak power should be more convenient from the point of view of interference effects.

\subsection{DRM+ and FM Broadcasting Coexistence and Related Work}

$\mathrm{DRM}+$ system brings advantages of digital systems. Thanks to an effective source coding, OFDM modulation format and FEC, usually a lower occupied bandwidth and a lower transmitted power are necessary to cover the comparable area by DRM+ compared to FM broadcasting [8]. The both type analog and digital audio broadcasting may coexist in VHF band II during some period [3]. But, introduction of any DRM+ system must be achieved with respect to existing FM broadcasting. Radio networks design requires knowledge of real system behavior. Evaluation of mutual interactions between systems is very important. Protection ratio (PR) is defined in [2] as the minimal acceptable ratio (in decibels) between a wanted signal and interfering signals to protect the reception of the wanted signal refer to a location probability at least of $50 \%$.

The DRM standard was first published by ETSI in 2001 (version 1.1). The mode E was adopted later in 2012 (version 3.2.1). But extension of DRM to frequencies above $30 \mathrm{MHz}$ was announced by the DRM consortium already in 2005. Spectrum usage parameters of DRM+ (mode E) are defined with respect to the internationally agreed standards in the VHF band II. Thus a frequency grid of $100 \mathrm{kHz}$ is recommended and $50 \mathrm{kHz}$ is possible occasionally. Various laboratory tests and field trials in VHF band II were done, which outlined useful results, findings and possible use cases of DRM+ regarding analog FM radio broadcasting.

First theoretical and experimental technical feasibility study was published in [9]. It summarized transmission and radio planning aspects. High speeds (up to $300 \mathrm{~km} / \mathrm{h}$ ), stationary, portable (indoors and outdoors) and mobile receiving conditions and single frequency network possibility were considered. A complete prototype transmission chain was assembled to verify theoretical results by measurements. A software and hardware concept was chosen, as digital signal processing based on software defined radio architecture is very appropriate approach for DRM+ signal processing. The minimum required carrier to noise power ratios (see Tab. 3 for 4PSK and 16QAM data carrier modulations) for demodulation were estimated in the case of an urban area environment for proposed system transmission parameters ( 0.5 code rate value was assumed). First protection ratio values were calculated for 16QAM and for 0.5 code rate (see Tab. 4 ). 


\begin{tabular}{|c|c|}
\hline $\begin{array}{c}\text { Data carrier } \\
\text { modulation }\end{array}$ & $\begin{array}{c}\text { Minimum required } \\
\mathbf{C} / \mathbf{N} \text { (dB) }\end{array}$ \\
\hline 4PSK & 15 \\
\hline 16QAM & 25 \\
\hline
\end{tabular}

Tab. 3. Minimum required carrier to noise power ratio $(\mathrm{C} / \mathrm{N})$ for demodulation according to the first technical feasibility study [9].

\begin{tabular}{|c|c|c|c|}
\hline \multicolumn{2}{|c|}{ DRM+ interfered with by FM } & \multicolumn{2}{|c|}{ FM interfered with by DRM+ } \\
\hline $\begin{array}{c}\text { Frequency } \\
\text { offset (kHz) }\end{array}$ & PR (dB) & $\begin{array}{c}\text { Frequency } \\
\text { offset (kHz) }\end{array}$ & PR (dB) \\
\hline 0 & 25 & 0 & 30 \\
\hline 100 & 25 & 100 & 30 \\
\hline 200 & -8 & 200 & 13.5 \\
\hline 300 & -40 & 300 & -9.5 \\
\hline 400 & -40 & 400 & -29 \\
\hline
\end{tabular}

Tab. 4. Protection ratio (PR) values according to the first technical feasibility study [9].

Initial results of protection ratios measurements are published in [10]. FM radio broadcasting interfered with by a DRM+ signal for various frequency offsets was measured in a laboratory. The goal of the paper was to verify the interference potential of the new digital broadcast systems. $\mathrm{DRM}+$ signal produced comparable interferences as an FM signal for offset lower than $300 \mathrm{kHz}$ and higher than $12000 \mathrm{kHz}$, whilst the interference potential of DRM+ was higher (12 dB maximally) for offsets between $300 \mathrm{kHz}$ and $12000 \mathrm{kHz}$ for the case of filtered DRM+ interfering signal.

First field trial of DRM+ in Kaiserslautern was presented in [11], [12], [13]. During trial, audio quality of FM transmission interfered with by FM signal and DRM+ signal was assessed. The results as dependencies on RF signal SNR were presented for frequency offsets from $0 \mathrm{kHz}$ to $300 \mathrm{kHz}$ for the case of useful FM signal. It was found out that DRM+ signal produced a slightly higher (from $3 \mathrm{~dB}$ to $5 \mathrm{~dB}$ ) interferences for the zero frequency offset (in the co-channel) in comparison with FM signal thanks to the fact that FM interfering signal has no amplitude variation. But for higher offsets $(100 \mathrm{kHz}, 200 \mathrm{kHz}$ and $300 \mathrm{kHz}$ were tested), interferences from DRM + and from FM seemed to be equivalent regarding interference potential. Also a preliminary measurement of DRM+ transmission interfered with by FM signal was done. The coverage of DRM+ transmission using 4PSK modulation was compared against to FM transmission interfered with by a FM signal for both stationary and mobile reception. Very useful general finding was that compatibility was much easier to achieve in real field tests than in laboratory tests.

Technical conditions allowing an introduction of $\mathrm{DRM}+$ to VHF band II was further verified in [11], [13], [3] on the basis of simulation. Coverage predictions for stationary receptions in the cases of both 4PSK and 16QAM data carrier modulations were made and compatibility was checked by a network planning software considering European radio regulations and coordination procedures valid for VHF band II. Planning was based on protection ratios (see Tab. 5) between a useful signal and an interfering signal and on frequency offset between signals. For the case of useful FM signal, DRM+ signal caused $5 \mathrm{~dB}$ higher interferences compared to an FM interfering signal for the zero offset and for $100 \mathrm{kHz}$ offset and on the contrary interferences from the DRM+ signal were considerably less for frequency offsets higher than $200 \mathrm{kHz}$. As compared the protection ratios, DRM+ was interfered with by FM considerably less compared to FM interfered with by DRM+ (protection ratios was at least $19 \mathrm{~dB}$ smaller) for the zero offset and for $100 \mathrm{kHz}$ offset. Moreover, interferences from FM to DRM+ were inconsiderable for frequency offsets higher than $200 \mathrm{kHz}$.

\begin{tabular}{|c|c|c|c|c|c|}
\hline \multicolumn{2}{|c|}{$\begin{array}{c}\text { DRM+ (16QAM) } \\
\text { interfered with by } \\
\text { FM }\end{array}$} & \multicolumn{2}{c|}{$\begin{array}{c}\text { DRM+ (4PSK) } \\
\text { interfered with by } \\
\text { FM }\end{array}$} & \multicolumn{2}{|c|}{$\begin{array}{c}\text { FM interfered with } \\
\text { by DRM+ }\end{array}$} \\
\hline $\begin{array}{c}\text { Frequenc } \\
\text { y offset } \\
\text { (kHz) }\end{array}$ & $\begin{array}{c}\text { PR } \\
\text { (dB) }\end{array}$ & $\begin{array}{c}\text { Frequency } \\
\text { offset } \\
\text { (kHz) }\end{array}$ & $\begin{array}{c}\text { PR } \\
\text { (dB) }\end{array}$ & $\begin{array}{c}\text { Frequency } \\
\text { offset (kHz) }\end{array}$ & $\begin{array}{c}\text { PR } \\
\text { (dB) }\end{array}$ \\
\hline 0 & 20 & 0 & 11 & 0 & 50 \\
\hline 100 & -4 & 100 & -13 & 100 & 38 \\
\hline 200 & -40 & 200 & -40 & 200 & -7 \\
\hline 300 & -40 & 300 & -40 & 300 & -40 \\
\hline 400 & -40 & 400 & -40 & 400 & -40 \\
\hline
\end{tabular}

Tab. 5. Protection ratio (PR) values for steady interference presented in [13].

Simulations [11], [13], [3] were based on two proposed scenarios with ten transmitting sites-a replacement scenario or an integration scenario. Replacement scenario means conversion of an existing FM transmitter to a DRM+ one, while integration scenario means an addition of a new DRM+ transmitter into the existing landscape (the case of integration is described as Hybrid DRM+ mode in [3]). To protect other existing FM radio stations in the case of the replacement scenario, power of DRM+ signal was $5 \mathrm{~dB}$ decreased compared to replaced FM broadcasting, nonetheless the predicted coverage of new DRM+ broadcasting was better (for the both 4PSK and 16QAM data carrier modulations) compared to the predicted coverage of the former FM radio broadcasting. In the case of the integration scenario, introduction of DRM + station was only possible with a power reduction ( $40 \mathrm{~dB}$ or more) as compared to typically used values for FM, resulting in a smaller coverage (even for 4PSK data carrier modulation) applicable to local audio broadcasting.

The latest findings in the area of the DRM+ and FM radio coexistence at the time of writing this paper follow. Protection ratios for FM broadcasting interfered with by DRM+ are evaluated in [2], [7], [14], [15], but only one failure criterion (decrease of SNR to value of $50 \mathrm{~dB}$ ) is chosen and only FM stereo mode is considered. The values determined by [15] and by [16] for various frequency offset between FM and DRM+ signals are presented in Tab. 6 .

Important regulatory aspects for DRM+ introduction are summarized in [7] and in [16] and protection ratios for DRM+ system interfered with by FM broadcasting are listed there. But, only two of eight combinations of protection levels and data carriers modulations of MSC are investigated there - protection level 1 together with 4PSK 


\begin{tabular}{|c|c|c|}
\hline $\begin{array}{c}\text { Frequency } \\
\text { offset (kHz) }\end{array}$ & $\begin{array}{c}\text { Protection } \\
\text { ratio (dB) [15] }\end{array}$ & $\begin{array}{c}\text { Protection } \\
\text { ratio (dB) [16] }\end{array}$ \\
\hline 0 & 49 & 49 \\
\hline \pm 100 & 30 & 33 \\
\hline \pm 200 & 3 & 7 \\
\hline \pm 300 & -8 & -7 \\
\hline \pm 400 & -11 & -11 \\
\hline \pm 500 & -13 & -13 \\
\hline \pm 1000 & -21 & -21 \\
\hline
\end{tabular}

Tab. 6. Protection ratios for FM broadcasting interfered with by DRM+ determined by [15] and by [16].

\begin{tabular}{|c|c|c|c|}
\hline \multicolumn{2}{|c|}{ PL1 / 4PSK } & \multicolumn{2}{c|}{ PL2 / 16QAM } \\
\hline $\begin{array}{c}\text { Frequency } \\
\text { offset (kHz) }\end{array}$ & $\begin{array}{c}\text { Protection } \\
\text { ratio (dB) }\end{array}$ & $\begin{array}{c}\text { Frequency } \\
\text { offset (kHz) }\end{array}$ & $\begin{array}{c}\text { Protection } \\
\text { ratio (dB) }\end{array}$ \\
\hline 0 & 11 & 0 & 18 \\
\hline \pm 100 & -13 & \pm 100 & -9 \\
\hline \pm 200 & -54 & \pm 200 & -49 \\
\hline \pm 300 & -76 & \pm 300 & -68 \\
\hline
\end{tabular}

Tab. 7. Protection ratios for DRM+ interfered with by FM broadcasting according to [16]

and protection level 2 with 16QAM. Table 7 shows recommended values of protection ratio presented in [16] for various frequency offset between DRM + and FM signals.

Results of works [14], [16] prove on the base of field measurements, that protection ratios are limited to frequency offsets in the range of $\pm 300 \mathrm{kHz}$ in the real reception conditions, because interferences for greater frequency offsets are not relevant.

The detailed analysis of DRM+ and FM broadcasting systems coexistence based on measurement of mutual interferences of each to other for frequency offsets in the range of $\pm 300 \mathrm{kHz}$ is done in this paper. Some brief results of preliminary measurements of interactions between DRM+ and FM broadcasting systems were already published in [17]. Different DRM+ modes (i.e. combinations of various protection levels and data carriers modulations in MSC channel) are assumed in the case of DRM+ reception interfered with by FM broadcasting. Corrections of protection ratios according to DRM+ protection levels useful for broadcasting networks planning are proposed in this paper. The modulation of interfering FM signal is clearly defined here and various modulating signal types are tested. The both mono and stereo reception FM broadcasting mode and various sound quality criteria are considered in the case of FM broadcasting reception interfered with by DRM+. The influence of DRM+ signal PAPR reduction on reception of interfered FM signal is evaluated here as well.

\section{Signal Quality Criteria}

For analysis of interactions measurement, one useful (wanted, desired) and one interfering (unwanted) signal are assumed. The wanted signal belongs to the system to be received and the unwanted signal comes from other interfering system. Then, the signal to interference power ratio (in decibels) can be determined:

$$
S I R=P_{\mathrm{S}}-P_{\mathrm{I}}
$$

where $P_{\mathrm{S}}$ is power of the useful RF signal and $P_{\mathrm{I}}$ is power of the interferer. Mainly, the minimal SIR value is searched, which is sufficient for reception of the desired signal under the below given criteria. Various signals spectra overlapping is considered with frequency offset between wanted and unwanted signals in range from $-300 \mathrm{kHz}$ to $300 \mathrm{kHz}$.

\subsection{Reception Criterion for DRM+}

As a reception criterion for DRM+ system, a reception without audio failures in MSC channel is chosen. The audio failure is meant here as more than one detected errors in output audio stream during ten second similarly as picture failure for digital television [18]. This criterion is simply applicable to domestic receivers and it is important criterion for ordinary users.

\subsection{Reception Criterion for FM Broadcasting}

As a reception criterion for FM broadcasting, the decrease to desired value of signal to noise power ratio (SNR) of demodulated AF output signal is considered. Four tested desired SNR values are $30 \mathrm{~dB}, 40 \mathrm{~dB}, 50 \mathrm{~dB}$ and $60 \mathrm{~dB}$ for the both mono and stereo modes. SNR is measured by a simple sequential method according to the standard [19]. A standardized band pass filter is inserted between an AF output and a voltmeter and thus the root mean square (RMS) voltage values of useful or noise signal can be measured. Firstly, the receiver is brought under standard measuring conditions. Secondly, frequency modulation is deactivated and RMS voltage value of noise at the output of the receiver is measured. Thirdly, modulation is activated at maximum frequency deviation and RMS voltage value of useful signal at the AF output of the receiver is measured. Signal to noise power ratio (in decibel) at the AF output of the receiver is computed as:

$$
S N R=20 \log \frac{v_{\mathrm{S}}}{v_{\mathrm{N}}}
$$

where $v_{\mathrm{S}}$ is RMS voltage value of useful signal and $v_{\mathrm{N}}$ is RMS voltage value of noise measured according to [19].

\section{Measurement of Mutual Interferences}

The goal of this paper is to analyze coexistence of the DRM+ and FM broadcasting systems on the base of the measurements. In the following sections the mutual interferences are investigated.

\subsection{DRM+ Interfered with by FM Broadcasting}

In this section, measurement is described and results 
are presented in the case of reception of DRM+ signal interfered with by FM radio broadcasting signal for various combinations of protection levels and data carriers modulation of MSC channel. The main aim is to compare various possible combinations. Moreover, various waveform types of modulating signal for interfering FM signal are set up. The minimal necessary value of $S I R$ is designated as $S I R_{\text {DRM }}$ here.

The measurement workplace is arranged according to the block diagram in Fig. 1. The both useful and interfering signals are combined by a combiner and fed to a receiver input. The following equipment is utilized to generate and to receive signals.

The Vector Signal Generator (VSG) Rohde\&Schwarz SMU200A generates the useful DRM+ signal. The VSG generator is externally excited by baseband analogue inphase and quadrature (IQ) component modulating signals from computer's digital to analog converter (supporting 24 bits and $192 \mathrm{kHz}$ sample frequency). IQ modulating signals are computed by the software Spark (version 15042013, trial license) [20] installed on the desktop personal computer (PC 1). A filtering and a PAPR reduction of IQ modulating signals can be applied by means of Spark software. For this case, filtering is applied with default setting and PAPR reduction is not processed. Spectral mask for DRM+ signal (defined by [2]) is accomplished.

The RF generator (RF Gen.) Rohde\&Schwarz SMY 02 provides interfering FM signal. The RF Gen. is externally excited by the output signal from a stereo coder. The stereo coder contains a pre-emphasis filter for the both stereo channel. Two AF generators (AF Gen. 1, AF Gen. 2) Agilent 33220A provide signals for stereo input signals of the stereo coder. Both input signals are filtered by standardized band pass filters (BPF 1, BPF 2) to pass signals in frequency range between $200 \mathrm{~Hz}$ and $15 \mathrm{kHz}$, characteristic of filters is defined in [19]. The same levels of output signals of both AF generators are set up in relation to RMS voltage value of the stereo multiplexed signal $-212.1 \mathrm{mV}$ value is kept constant at the output of the stereo coder. Thus the average power of modulating signal is equivalent to the power of a sinusoidal tone which causes a frequency peak deviation of $22.5 \mathrm{kHz}$ representing the standard value of frequency deviation for FM broadcasting. This level corresponds to $1.5 \mathrm{dBr}$ of modulation power according to [21]. Two different waveform types of the modulating signal for FM are set up - the sinusoidal tone with $1 \mathrm{kHz}$ frequency and additive white Gaussian noise signal. The stereo coder can be operated in one of three possible modes:

- Only one input is active and the same signal is passed to the both stereo channels $(\mathrm{L}=\mathrm{P})$.

- Only one input is active and the opposite signals are passed to stereo channels $(\mathrm{L}=-\mathrm{P})$.

- The both inputs are active and independent signals can be in $\mathrm{L}$ and $\mathrm{P}$ stereo channels.

A software defined radio (SDR) conception for $\mathrm{DRM}+$ reception is employed. Combined DRM + signal with interfering FM signal are pre-selected and frequency down-converted to inter-mediate frequency (IF) of 10.7 MHz by the communication receiver (Comm. Rec.) AOR AR5000. The IF frequency bandwidth is $110 \mathrm{kHz}$. Automatic gain control is deactivated on the Comm. Rec. SDR processing of IF signal follows. Universal Software Radio Peripheral (USRP) unit samples the signal [22] and sends samples via universal serial bus to a personal computer (PC 2), where DRM+ reception is achieved by SoDiRa software (version 0.099, demo version) [23].

Useful DRM+ signal has the power of $-60 \mathrm{dBm}$ and central carrier is on $107.5 \mathrm{MHz}$. FM carrier frequency is changed to achieve frequency offset between DRM + and FM signal in range from $-300 \mathrm{kHz}$ to $300 \mathrm{kHz}$. FM signal power is adjusted to fulfill $\mathrm{DRM}+$ reception criterion, in order the $S I R_{\mathrm{DRM}}$ value to be found for each frequency offset value. The spectrum analyzer (SA) Rohde\&Schwarz FSV verifies power levels and spectra of signals when needed. Table 8 summarizes the setup of the workplace for better orientation in the coexistence use case.

Measured dependences of $S I R_{\mathrm{DRM}}$ on the frequency offset are presented in Fig. 2-6. As the absolute value of frequency offset increases, $S I R_{\mathrm{DRM}}$ decreases with sharp drop in range from $50 \mathrm{kHz}$ to $200 \mathrm{kHz}$. Only slight decrease continues for the absolute value of frequency offset higher than $200 \mathrm{kHz}$.

Figure 2 shows results in the case of sinusoidal tone as FM modulating signal for the same signals in both stereo channels $\mathrm{L}=\mathrm{P}$ (matching to mono FM mode) and for the opposite signals $\mathrm{L}=-\mathrm{P}$ (matching to stereo FM mode). Combination of 16QAM and PL2 for DRM+ is chosen for

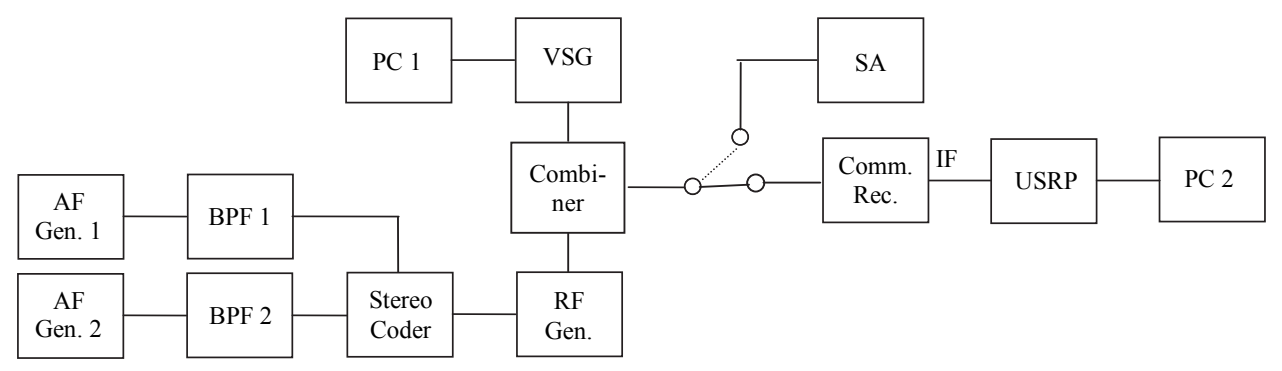

Fig. 1. Measurement block diagram for DRM+ interfered with by FM broadcasting. 


\begin{tabular}{|c|c|}
\hline Device & Specification \\
\hline $\begin{array}{l}\text { VSG (Vector } \\
\text { Signal Generator) }\end{array}$ & $\begin{array}{l}\text { The useful DRM+ signal generation: external IQ } \\
\text { modulation; }-60 \mathrm{dBm} \text { output level; } 107.5 \mathrm{MHz} \\
\text { central carrier frequency }\end{array}$ \\
\hline $\begin{array}{l}\text { PC } 1 \text { (Personal } \\
\text { Computer) }\end{array}$ & $\begin{array}{c}\text { Software generation of IQ modulating } \\
\text { components: } 24 \text { bits / } 192 \mathrm{kHz} \text { sample } \\
\text { frequency DAC }\end{array}$ \\
\hline $\begin{array}{c}\text { RF Gen. } \\
\text { (RF Generator) }\end{array}$ & $\begin{array}{l}\text { The interfering FM signal generation: external } \\
\text { FM modulation; carrier frequency changed from } \\
\text { 107.2 MHz to } 107.8 \mathrm{MHz} \text {; output level adjusted } \\
\text { to fulfill DRM+ reception criterion }\end{array}$ \\
\hline Stereo Coder & $\begin{array}{l}\text { Stereo multiplex coding, pre-emphasis filtration: } \\
212.1 \mathrm{mV} \text { RMS voltage level of output signal; } \\
\mathrm{L}=\mathrm{P} / \mathrm{L}=-\mathrm{P} / \text { independent } \mathrm{L} \text { and } \mathrm{P} \text { signals }\end{array}$ \\
\hline $\begin{array}{c}\text { AF Gen. } 1 \\
\text { (AF Generator) }\end{array}$ & $\begin{array}{l}\text { Generation of the first AF input signal for stereo } \\
\text { coder: } 1 \mathrm{kHz} \text { sinusoidal tone / additive white } \\
\text { Gaussian noise }\end{array}$ \\
\hline $\begin{array}{c}\text { AF Gen. } 2 \\
\text { (AF Generator) }\end{array}$ & $\begin{array}{l}\text { Generation of the second AF input signal for } \\
\text { stereo coder: } 1 \mathrm{kHz} \text { sinusoidal tone / additive } \\
\text { white Gaussian noise }\end{array}$ \\
\hline $\begin{array}{c}\text { BPF 1 } \\
\text { (Band Pass Filter) }\end{array}$ & $\begin{array}{l}\text { Filtration of the first AF input signal for stereo } \\
\text { coder: Pass band from } 200 \mathrm{~Hz} \text { to } 15 \mathrm{kHz}\end{array}$ \\
\hline $\begin{array}{c}\text { BPF } 2 \\
\text { (Band Pass Filter) }\end{array}$ & $\begin{array}{l}\text { Filtration of the second AF input signal for } \\
\text { stereo coder: Pass band from } 200 \mathrm{~Hz} \text { to } 15 \mathrm{kHz}\end{array}$ \\
\hline Combiner & $\begin{array}{l}\text { The useful DRM+ signal and the interfering FM } \\
\text { signal combination }\end{array}$ \\
\hline $\begin{array}{l}\text { Comm. Rec. } \\
\text { (Communication } \\
\text { Receiver) }\end{array}$ & $\begin{array}{l}\text { Pre-selection and frequency down-conversion of } \\
\text { signals: } 107.5 \mathrm{MHz} \text { tuned frequency; } 110 \mathrm{kHz} \\
\text { RF bandwidth; } 10.7 \mathrm{MHz} \text { IF frequency output }\end{array}$ \\
\hline $\begin{array}{l}\text { USRP (Universal } \\
\text { Software Radio } \\
\text { Peripheral unit) }\end{array}$ & $\begin{array}{l}\text { IF signal sampling, samples transfer via USB to } \\
\text { PC }\end{array}$ \\
\hline $\begin{array}{l}\text { PC } 2 \text { (Personal } \\
\text { Computer) }\end{array}$ & $\begin{array}{l}\text { DRM+ reception on the base of software defined } \\
\text { radio conception }\end{array}$ \\
\hline $\begin{array}{l}\text { SA (Spectrum } \\
\text { Analyzer) }\end{array}$ & $\begin{array}{c}\text { Verification of the power levels and spectra of } \\
\text { signals }\end{array}$ \\
\hline
\end{tabular}

Tab. 8. Setup of the workplace for measurement of DRM+ interfered with by FM broadcasting.

useful DRM+ signal. Stereo FM signal causes higher interferences than mono FM signal, the useful signal must be $28 \mathrm{~dB}$ higher in the worst case (for $100 \mathrm{kHz}$ offset).

Results of measurement for noise modulating signal are in Fig. 3 for the same signals in both stereo channels $\mathrm{L}=\mathrm{P}$ (mono $\mathrm{FM}$ mode), for the opposite signals $\mathrm{L}=-\mathrm{P}$ (stereo FM mode) and for two independent noise stereo signals (stereo FM mode). Combination of 16QAM and $\mathrm{PL} 2$ for DRM+ is chosen for useful DRM+ signal. Mono FM signal causes the lowest interferences, while stereo FM signal with opposite modulating stereo channels induces the highest interferences. In real, case of opposite stereo modulating signal is not usual. Comparing results for sinusoidal and noise modulating signal, it is evident that FM signal in case of noise modulating signal produces higher interferences for the absolute value of frequency offset between $50 \mathrm{kHz}$ and $200 \mathrm{kHz}$.

The main results are in Figs. 4-6, where various possible modes (given by combination of protection levels and data carriers modulations) of useful DRM+ signal are presented. Independent noise modulating signal in both stereo channels for FM interfering signal is used. To keep clarity, only results of three selected modes are depicted in Fig. 4 and results for other modes are presented in Figs. 5 and 6 as differences. Description of three selected modes and reasons for selection are summarized in Tab. 9. The shape (described above already) of measured dependences is almost the same for various modes, but dependences are shifted in the direction of the vertical axis. The differences are crucial for coverage of DRM + system. The higher necessary $S I R_{\mathrm{DRM}}$ leads to the smaller coverage.

The influence of the data carriers modulation can be evaluated by comparison of modes with the same code rate-16QAM / PL2 and 4PSK/PL3. To receive interfered DRM+ signal using 16QAM data carriers modulation, $S I R_{\mathrm{DRM}}$ must be $5-6 \mathrm{~dB}$ higher compared to 4PSK.

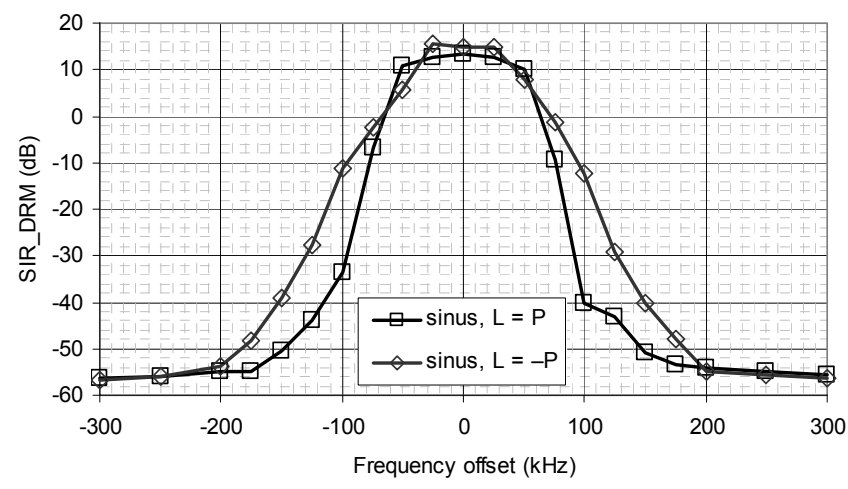

Fig. 2. Results of measurement of DRM + interfered with by FM broadcasting - combination of 16QAM and PL2 for DRM+ chosen, sinusoidal modulating signal set up for $\mathrm{FM}$ interfering signal $(\mathrm{L}=\mathrm{P}$ and $\mathrm{L}=-\mathrm{P}$ tested $)$.

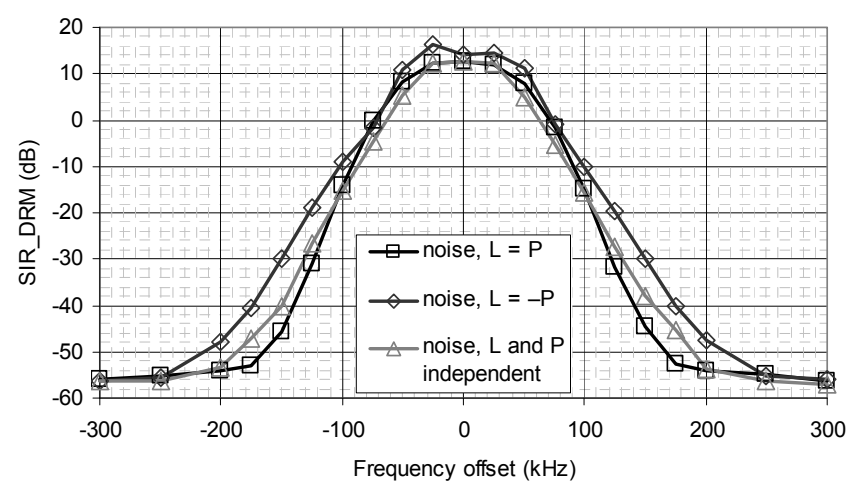

Fig. 3. Results of measurement of DRM+ interfered with by FM broadcasting - combination of 16QAM and PL2 for DRM+ chosen, noise modulating signal set up for FM interfering signal $(\mathrm{L}=\mathrm{P}, \mathrm{L}=-\mathrm{P}$ and independent stereo channels tested).

\begin{tabular}{|c|c|}
\hline $\begin{array}{c}\text { Data carriers } \\
\text { modulations / } \\
\text { protection levels }\end{array}$ & Reasons of selection \\
\hline 16QAM / PL2 & $\begin{array}{c}\text { Preferred mode with 16QAM modulation in } \\
{[2],[7],[14] ; \text { chosen as reference mode for }} \\
\text { modes with 16QAM modulation }\end{array}$ \\
\hline 4PSK / PL1 & $\begin{array}{c}\text { Preferred mode with 4PSK modulation in } \\
{[2],[7],[14] ; \text { chosen as reference mode for }} \\
\text { modes with 4PSK modulation }\end{array}$ \\
\hline 4PSK / PL3 & $\begin{array}{c}\text { Using the same code rate as 16QAM / PL2; } \\
\text { the influence of modulation can be evaluated }\end{array}$ \\
\hline
\end{tabular}

Tab. 9. Data carriers modulations and protection levels of selected DRM+ modes and the reasons of selection. 


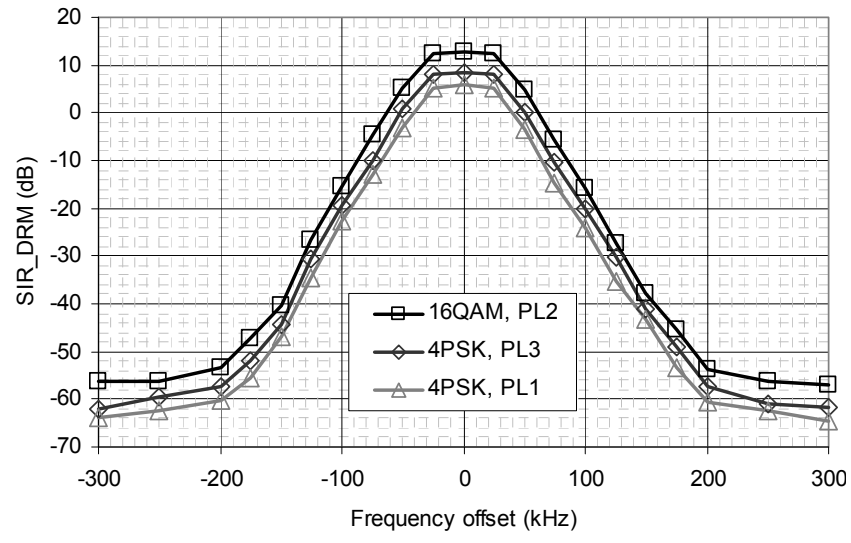

Fig. 4. Results of measurement of DRM+ interfered with by FM broadcasting (independent noise modulating signals in both stereo channels for FM interfering signal) for three selected combinations of data carriers modulation and protection levels of MSC channel.

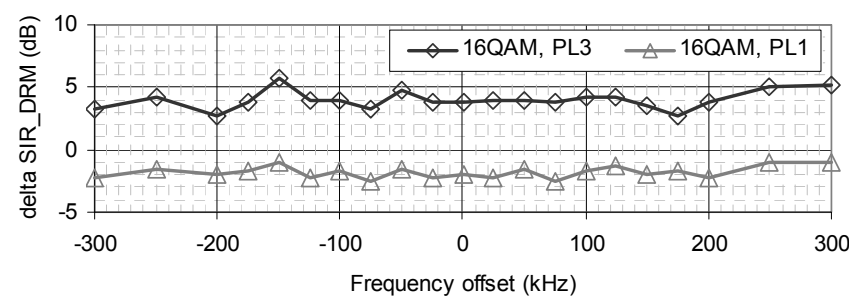

Fig. 5. Results of measurement of DRM+ interfered with by FM broadcasting (independent noise modulating signals in both stereo channels for FM interfering signal) - comparison of various protection levels of DRM+ for 16QAM data carriers modulation, differences plotted (the reference combination is 16QAM / PL2).

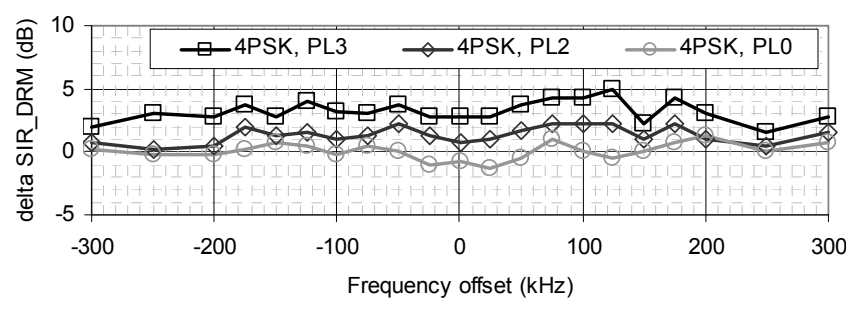

Fig. 6. Results of measurement of DRM+ interfered with by FM broadcasting (independent noise modulating signals in both stereo channels for FM interfering signal) - comparison of various protection levels of $\mathrm{DRM}+$ for 4PSK data carriers modulation, differences plotted (the reference combination is 4PSK / PL1).
To present and compare various DRM+ modes using 16QAM data carriers modulation, differences of measured $S I R_{\mathrm{DRM}}$ are computed for protection levels PL1 and PL2:

$$
\delta \operatorname{SIR}_{\mathrm{DRM}}(\Delta f)=\operatorname{SIR}_{\mathrm{DRM}}(\Delta f)-\operatorname{SIR}_{\mathrm{DRM}}^{16 \mathrm{QAM}, \mathrm{PL} 2}(\Delta f)
$$

where $S I R_{\mathrm{DRM}}^{16 \mathrm{QAM}, \mathrm{PL} 2}$ denotes values of $S I R_{\mathrm{DRM}}$ for reference mode-16QAM / PL2 and $\Delta f$ stands for frequency offset. The results are plotted in Fig. 5. More robust mode PL1 (than PL2) brings desirable $2 \mathrm{~dB}$ decrease of $S I R_{\mathrm{DRM}}$, while less robust mode PL3 leads to approx. $4 \mathrm{~dB}$ increase.

To present and compare various DRM+ modes using 4PSK data carriers modulation, differences of measured $S I R_{\text {DRM }}$ are computed for protection levels PL0, PL2 and PL3:

$$
\delta \operatorname{SIR}_{\mathrm{DRM}}(\Delta f)=\operatorname{SIR}_{\mathrm{DRM}}(\Delta f)-\operatorname{SIR}_{\mathrm{DRM}}^{4 \mathrm{PSK}, \mathrm{PL} 1}(\Delta f)
$$

where $S I R_{\mathrm{DRM}}^{4 \mathrm{PSK}, \mathrm{PL} 1}$ denotes values of $S I R_{\mathrm{DRM}}$ for reference mode-4PSK / PL1 and $\Delta f$ stands for frequency offset. The results are plotted in Fig. 6. More robust mode PL0 (than PL1) brings approx. $1 \mathrm{~dB}$ decrease of $S I R_{\mathrm{DRM}}$ but only for frequency offset from $-25 \mathrm{kHz}$ to $25 \mathrm{kHz}$. Less robust mode PL2 needs approx. $2 \mathrm{~dB}$ higher $S I R_{\mathrm{DRM}}$ for frequency offset from $-175 \mathrm{kHz}$ to $175 \mathrm{kHz}$ and the least robust mode even requires approx. $4 \mathrm{~dB}$ higher $S I R_{\mathrm{DRM}}$. Differences are higher for 16QAM data carriers modulation.

\subsection{FM Broadcasting Interfered with by DRM+}

In this section, measurement is described and results are presented for the case of reception of FM signal interfered with by DRM+ signal considered various $S N R$ for the both mono and stereo FM modes. Also the influence of the PAPR reduction of DRM+ signal on the interfered FM signal reception is examined. The minimal required value of $S I R$ is denoted as $S I R_{\mathrm{FM}}$ here.

The measurement workplace is arranged according to the block diagram in Fig. 7. The both useful and interfering signals are combined by a combiner and fed to a FM receiver. The following equipment is utilized to generate and receive signals.

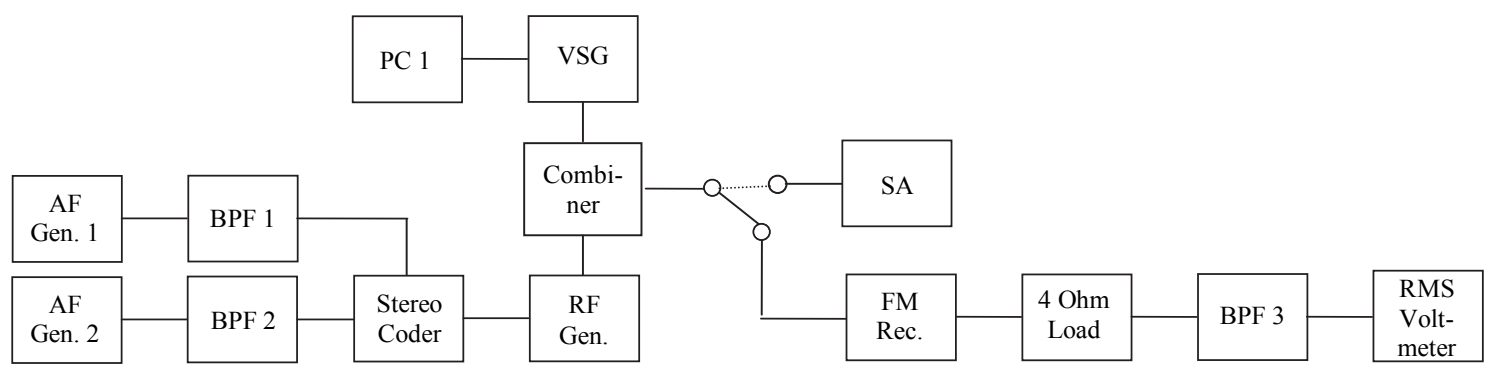

Fig. 7. Measurement block diagram for FM broadcasting interfered with by DRM+. 
RF generator (RF Gen.) is employed to generate a useful FM signal. The sinusoidal tone with $1 \mathrm{kHz}$ frequency is activated on AF generators (AF Gen. 1, AF Gen. 2) Agilent $33220 \mathrm{~A}$ as modulating signals. RMS voltage levels on the both AF generators are set up to satisfy the maximal frequency deviation of $75 \mathrm{kHz}$. Band pass filters (BPF 1, BPF 2) between AF generators and a stereo coder do not affect $1 \mathrm{kHz}$ sinusoidal tone. The stereo coder allows deactivation of stereo coding process to provide FM mono mode. A stereo pilot tone is well generated or not according to the stereo or mono mode selection respectively.

Interfering DRM+ signal is generated similarly as described in Sec. 4.1. But here, two cases are consideredwithout and with the PAPR reduction (PAPR is reduced from $11.5 \mathrm{~dB}$ to $8 \mathrm{~dB}$ by peak windowing method). Selected data carriers modulation and protection level do not influence the shape of the DRM+ signal spectrum, combination of 16QAM and PL2 is chosen. Spectral mask for DRM+ signal (defined by [2]) is passed for the both cases of without and with the PAPR reduction.

Interfered FM signal is processed by the modern domestic FM receiver (FM Rec.) Sangean DPR-202. AF output is terminated by the $4 \mathrm{Ohm}$ load. Output signal is filtered by band pass filter (BPF 3) to pass signal in frequency range between $200 \mathrm{~Hz}$ and $15 \mathrm{kHz}$ (the character-

\begin{tabular}{|c|c|}
\hline Device & Specification \\
\hline $\begin{array}{c}\text { RF Gen. } \\
\text { (RF Generator) }\end{array}$ & $\begin{array}{l}\text { The useful FM signal generation: external FM } \\
\text { modulation; } 75 \mathrm{kHz} \text { maximal frequency } \\
\text { deviation; } 107.5 \mathrm{MHz} \text { carrier frequency; output } \\
\text { level adjusted to fulfill FM reception criterion }\end{array}$ \\
\hline Stereo Coder & $\begin{array}{c}\text { Stereo multiplex coding: } 707 \mathrm{mV} \text { RMS voltage } \\
\text { level of output signal; } \mathrm{L}=\mathrm{P} \text { (mono) / } \\
\text { independent } \mathrm{L} \text { and } \mathrm{P} \text { signals (stereo) }\end{array}$ \\
\hline $\begin{array}{c}\text { AF Gen. } 1 \\
\text { (AF Generator) }\end{array}$ & $\begin{array}{l}\text { Generation of the first AF input signal for stereo } \\
\text { coder: } 1 \mathrm{kHz} \text { sinusoidal tone }\end{array}$ \\
\hline $\begin{array}{c}\text { AF Gen. } 2 \\
\text { (AF Generator) }\end{array}$ & $\begin{array}{l}\text { Generation of the second AF input signal for } \\
\text { stereo coder: } 1 \mathrm{kHz} \text { sinusoidal tone }\end{array}$ \\
\hline $\begin{array}{c}\text { BPF 1 } \\
\text { (Band Pass Filter) }\end{array}$ & Does not affect $1 \mathrm{kHz}$ sinusoidal tone. \\
\hline $\begin{array}{c}\text { BPF } 2 \\
\text { (Band Pass Filter) }\end{array}$ & Does not affect $1 \mathrm{kHz}$ sinusoidal tone. \\
\hline $\begin{array}{c}\text { VSG (Vector } \\
\text { Signal Generator) }\end{array}$ & $\begin{array}{c}\text { The interfering DRM+ signal generation: } \\
\text { external IQ modulation; }-66 \mathrm{dBm} \text { output level; } \\
\text { central carrier frequency from changed } \\
107.2 \mathrm{MHz} \text { to } 107.8 \mathrm{MHz}\end{array}$ \\
\hline $\begin{array}{l}\text { PC } 1 \text { (Personal } \\
\text { computer) }\end{array}$ & $\begin{array}{c}\text { Software generation of IQ modulating } \\
\text { components: } 24 \text { bits / } 192 \mathrm{kHz} \text { sample } \\
\text { frequency DAC }\end{array}$ \\
\hline Combiner & $\begin{array}{c}\text { The useful FM signal and the interfering DRM+ } \\
\text { signal combination }\end{array}$ \\
\hline $\begin{array}{c}\text { FM Rec. } \\
\text { (FM Receiver) }\end{array}$ & FM reception: $107.5 \mathrm{MHz}$ frequency tuned \\
\hline 4 Ohm Load & Termination of the receiver output signal \\
\hline $\begin{array}{c}\text { BPF } 3 \\
\text { (Band Pass Filter) }\end{array}$ & $\begin{array}{l}\text { Filtration of demodulated AF signal: Pass band } \\
\text { from } 200 \mathrm{~Hz} \text { to } 15 \mathrm{kHz}\end{array}$ \\
\hline RMS Voltmeter & $\begin{array}{l}\text { RMS voltage measuring of filtered demodulated } \\
\text { AF signal }\end{array}$ \\
\hline $\begin{array}{l}\text { SA (Spectrum } \\
\text { Analyzer) }\end{array}$ & $\begin{array}{l}\text { Verification of the power levels and spectra of } \\
\text { signals }\end{array}$ \\
\hline
\end{tabular}

Tab. 10.Setup of the workplace for measurement of FM broadcasting interfered with by DRM+. istic of the filter is defined by [19]). RMS voltage value of the filtered demodulated AF signal is measured by the voltmeter Tesla BM 543.

Useful FM signal is generated on frequency of 107.5 MHz. The FM signal power level is adjusted according to the FM reception criterion, while interfering $\mathrm{DRM}+$ signal has constant power level of $-66 \mathrm{dBm}$. Central frequency of DRM+ signal is changed to achieve frequency offset between signals in range from $-300 \mathrm{kHz}$ to $300 \mathrm{kHz}$. The necessary $S I R_{\mathrm{FM}}$ value is found for each frequency offset value. The spectrum analyzer (SA) can verify power levels and spectra of signals. Table 10 summarizes the setup of the workplace for better orientation in the coexistence use case.

Measured $S I R_{\mathrm{FM}}$ dependences on the frequency offset are depicted in Fig. 8 for the stereo FM mode and in Fig. 9 for the mono FM mode in the case of no PAPR reduction. Four desired $S N R$ values are tested-30 dB, $40 \mathrm{~dB}, 50 \mathrm{~dB}$ and $60 \mathrm{~dB}\left(S I R_{\mathrm{FM}}\right.$ and $S N R$ do not relate in a linear way in regard to non-linear FM modulation). As absolute value of frequency offset increases, $S I R_{\mathrm{FM}}$ decreases. Two border values of frequency offset can be seen $-75 \mathrm{kHz}$ and

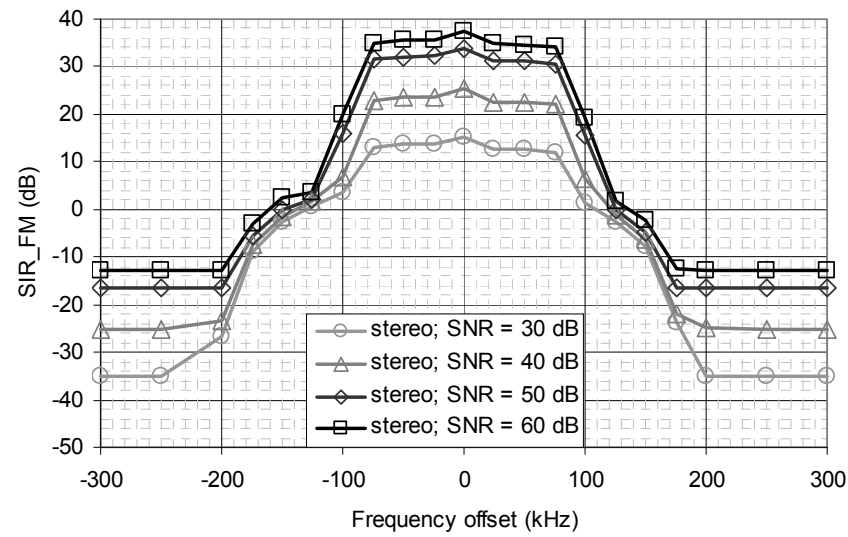

Fig. 8. Results of measurement of FM broadcasting interfered with by DRM+—-stereo FM mode tested, four desired $S N R$ values considered, PAPR of DRM+ signal not reduced.

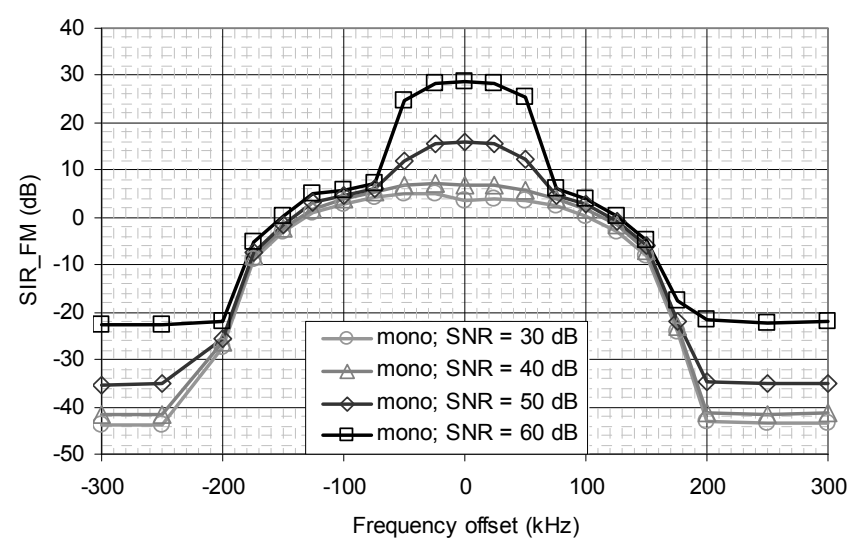

Fig. 9. Results of measurement of FM broadcasting interfered with by DRM+-mono FM mode tested, four desired $S N R$ values considered, PAPR of DRM+ signal not reduced. 
$200 \mathrm{kHz}$ as examples for the stereo FM mode. $S I R_{\mathrm{FM}}$ decreases very slowly for absolute values of frequency offset lower than $75 \mathrm{kHz}$. SIR $\mathrm{FM}$ decreases sharply for absolute values of frequency offset in range from $75 \mathrm{kHz}$ to $200 \mathrm{kHz}$. The values of $S I R_{\mathrm{FM}}$ remain almost constant for absolute values of frequency offset higher than $200 \mathrm{kHz}$.

To evaluate the influence of interfering signal PAPR reduction, $S I R_{\mathrm{FM}}$ is measured again with activated PAPR reduction of DRM+ signal. Because of very similar results, differences of measured $S I R_{\mathrm{FM}}$ are computed:

$$
\delta \operatorname{SIR}_{\mathrm{FM}}(\Delta f)=\operatorname{SIR}_{\mathrm{FM}}(\Delta f)-\operatorname{SIR}_{\mathrm{FM}}^{\text {no red }}(\Delta f)
$$

where $S I R_{\mathrm{FM}}^{\text {no red }}$ denotes values of $S I R_{\mathrm{FM}}$ for the case of no PAPR reduction and $\Delta f$ stands for frequency offset. Results are plotted in Fig. 10 for stereo FM mode and in Fig. 11 for mono FM mode. Very fluctuated results for the stereo FM mode do not prove relevant influence of PAPR reduction. While for mono FM mode, PAPR reduction of interfering $\mathrm{DRM}+$ signal causes desirable decrease of $S I R_{\mathrm{FM}}$ for $100 \mathrm{kHz}$ frequency offset (approx. $1.5 \mathrm{~dB}$ for $50 \mathrm{~dB} S N R$ as example) and it causes a slight increase of $S I R_{\mathrm{FM}}$ for $200 \mathrm{kHz}$ frequency offset (almost $1 \mathrm{~dB}$ for $50 \mathrm{~dB} S N R$ as example).

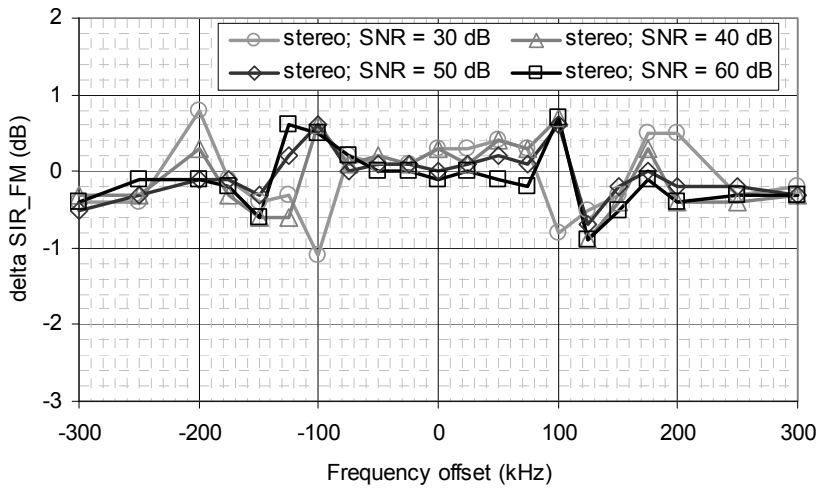

Fig. 10. Results of measurement of FM broadcasting interfered with by DRM+-influence of DRM+ signal PAPR reduction presented, stereo FM mode tested, four desired $S N R$ values considered, differences plotted (in relation to measurement without PAPR reduction).

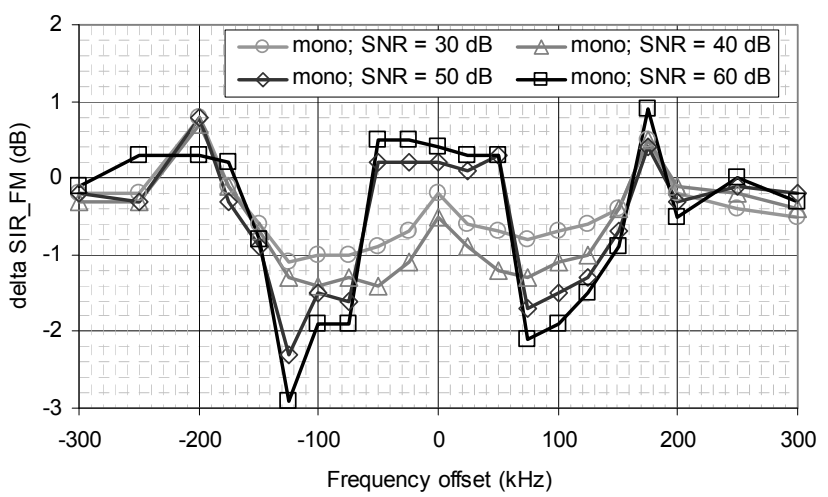

Fig. 11. Results of measurement of FM broadcasting interfered with by DRM+-influence of DRM+ signal PAPR reduction presented, mono FM mode tested, four desired $S N R$ values considered, differences plotted (in relation to measurement without PAPR reduction).

\subsection{Discussion of Results}

Firstly, DRM+ reception interfered with by FM broadcasting was examined. Mono FM signal caused lower interferences generally. The highest interferences were in case of opposite modulating stereo channels, but it is not a usual case in real. Compared to sinusoidal signals, noise modulating signals induced higher interferences. Various DRM + modes were tested subsequently interfered with by stereo FM signal modulated by independent noise signals in both stereo channels. The differences for various modes are crucial for coverage design of DRM + system. On the basis of measurement results in this paper, the corrections of protection ratios presented in Tab. 7 are proposed for other DRM+ modes. Table 11 shows the proposed corrections for modes with 16QAM data carrier modulation (the reference mode is PL2/16QAM). Table 12 summarizes the proposed corrections for modes with 4PSK data carrier modulation (the reference mode is PL1 / 4PSK).

\begin{tabular}{|c|c|c|}
\cline { 2 - 3 } \multicolumn{1}{c|}{} & \multicolumn{2}{c|}{ Protection ratio correction (dB) } \\
\hline $\begin{array}{c}\text { Frequency } \\
\text { offset (kHz) }\end{array}$ & PL1 / 16QAM & PL3 / 16QAM \\
\hline 0 & -2 & +4 \\
\hline \pm 100 & -1.5 & +4 \\
\hline \pm 200 & -2 & +4 \\
\hline \pm 300 & -1 & +5 \\
\hline
\end{tabular}

Tab. 11. Proposed corrections of protection ratios presented in Tab. 7 for modes with 16QAM data carrier modulation (reference mode PL2 / 16QAM).

\begin{tabular}{|c|c|c|c|}
\cline { 2 - 4 } \multicolumn{1}{c|}{} & \multicolumn{3}{c|}{ Protection ratio correction (dB) } \\
\hline $\begin{array}{c}\text { Frequency } \\
\text { offset (kHz) }\end{array}$ & PL0 / 4PSK & PL2 / 4PSK & PL3 / 4PSK \\
\hline 0 & -1 & +1 & +3 \\
\hline \pm 100 & 0 & +2 & +4 \\
\hline \pm 200 & 0 & +1 & +3 \\
\hline \pm 300 & 0 & +1 & +3 \\
\hline
\end{tabular}

Tab. 12.Proposed corrections of protection ratios presented in Tab. 7 for modes with 4PSK data carrier modulation (reference mode PL1 / 4PSK).

Secondly, FM broadcasting reception interfered with by DRM+ was investigated. Four desired $S N R$ values were tested. The influence of DRM+ signal PAPR reduction was subsequently evaluated from the viewpoint of interference effects. No relevant influence was proved for the stereo FM mode. For mono FM mode, PAPR reduction caused a slightly better reception for $100 \mathrm{kHz}$ frequency offset and a slightly worse reception for $200 \mathrm{kHz}$ frequency offset.

Even though different reception criteria were applied for DRM+ and FM broadcasting, measurement results demonstrated that DRM+ offers higher robustness, when it was interfered with by FM radio broadcasting compared to FM radio broadcasting interfered with by DRM+ (considered stereo FM mode and $S N R$ of $40 \mathrm{~dB}$ at least).

\section{Conclusion}

This paper analyzed the coexistence of DRM Plus and 
FM broadcasting based on the measurement of mutual interferences. Different DRM Plus modes were assumed in the case of DRM Plus reception interfered with by FM broadcasting. The results made possible to propose the corrections of protection ratios according to DRM Plus protection levels for almost all DRM Plus modes (Tabs. 11 and 12). The both mono and stereo FM mode and various sound quality criteria were considered in the case of FM broadcasting reception interfered with by DRM Plus. The influence of PAPR reduction of interfering DRM Plus signal was slightly proved only for FM mono mode.

The influence of PAPR reduction of DRM Plus signal is planned to be more examined in the future work. The impact on the reception of DRM Plus signal after PAPR reduction is an interesting object of investigation.

\section{Acknowledgments}

This work was supported by the Grant Agency of the Czech Technical University in Prague, grants No. SGS13/206/OHK3/3T/13, No. SGS14/204/OHK3/3T/13.

\section{References}

[1] DEUTSCHES DRM-FORUM. Considerations for the digital transition of local and regional terrestrial broadcast radio in Germany. At Symposium The Way to Digital Broadcast by DAB and DRM+ for Local Radio and Community Media - Milestones in Rhineland-Palatinate, Germany and Europe. Kaiserslautern (Germany), 2014

[2] EUROPEAN CONFERENCE OF POSTAL AND TELECOMMUNICATIONS ADMINISTRATIONS. Future possibilities for the digitalisation of band II (87.5-108 MHz). Technical supplement to ECC Report 141, 2012

[3] LENHERT, J. Leaving the dead-end street: New ways for the digitisation of the VHF-FM sound broadcasting with DRM+. Part II: First results on compatibility planning of DRM+ and HDRadioTM in the VHF band. In Proceedings of the 9th Workshop Digital Broadcasting. Fraunhofer Institute for Integrated Circuits IIS Erlangen, Germany, Heinz Gerhäuser (Ed.), 2008

[4] DOBES, J., ZALUD, V. Modern Radio Engineering. (in Czech) Prague: BEN, 2006. ISBN 80-7300-132-2

[5] EUROPEAN TELECOMMUNICATIONS STANDARDS INSTITUTE. Digital Radio Mondiale (DRM); System Specification. ETSI ES 201980 V4.1.1, 2014

[6] DVORSKY, M. Modern digital technologies alternatively used beside Digital Audio Broadcasting system. In Wofex 2006. Ostrava (Czech Rep.), 2006, p. 446-450. ISBN 80-248-1152-9

[7] DIGITAL RADIO MONDIALE CONSORTIUM. DRM Introduction and Implementation Guide. Rev. 2, 2013

[8] KIM, J. S., BAEK, M. S., LEE, Y. T., KIM, K. S. The optimal placement of radio stations in coexisting DRM+ and analog FM systems. IEEE Transactions on Consumer Electronics, 2013, vol. 59, no. 4, p. 738-746. DOI: 10.1109/TCE.2013.6689684

[9] STEIL, A., KREUTZER, M., FEILEN, M., LEHNERT, J., URBANSKY, R., SAUER-GREFF, W. Technical feasibility study and field trial concept for DRM-based digital radio in the VHF-FM radio band. In Proceedings of the 7th Workshop Digital Broadcasting. Fraunhofer Institute for Integrated Circuits IIS Erlangen, Germany, Heinz Gerhäuser (Ed.), 2006, p. 67-72.

[10] HASENPUSCH, T., SCHAD, F., EFFINGER, R. Documentation G531/00328/07, Compatibility Measurements DRM120, DRM and $H D$ Radio interfering with FM Broadcast, Narrowband FM (BOS) and Aeronautical Radionavigation. German Network Agency and University of Applied Science of Kaiserslautern, 2007

[11] STEIL, A., SCHAD, F., FEILEN, M., KÖHLER, M., LEHNERT, J., HEDRICH, E., KILIAN, G. Digitizing VHF sound broadcasting with DRM+ (Mode E). In Proceedings of the IEEE International Symposium on Broadband Multimedia Systems and Broadcast. Bilbao, Spain, 2009. ISBN 978-1-244-2591-4, DOI: 10.1109/ISBMSB.2009.5133727

[12] STEIL, A., SCHAD, F., FEILEN, M., HEDRICH, E. Leaving the dead-end street: New ways for the digitisation of the VHF-FM sound broadcasting with DRM+. Part I DRM+ field trial: Concept, setup and first results. In Proceedings of the 9th Workshop Digital Broadcasting. Fraunhofer Institute for Integrated Circuits IIS Erlangen, Germany, Heinz Gerhäuser (Ed.), 2008

[13] STEIL, A., LEHNERT, J., SCHAD, F., KÖHLER, M. Leaving the dead-end street: New ways for the digitisation of the VHF-FM sound broadcasting with DRM+. In Proceedings of the 10th Workshop Digital Broadcasting. Fraunhofer Institute for Integrated Circuits IIS Erlangen, Germany, Heinz Gerhäuser (Ed.), 2009 , p. $8-22$

[14] UNIVERSITY OF APPLIED SCIENCES OF KAISERSLAUTERN. Protection ratios for FM interfered with by digital broadcasting signals, compilation of results of present investigations, thoughts on protection ratio values and on appropriate measurement concepts. Report for ECC FM PT45, 2010

[15] GERMAN DRM PLATFORM. Planning Parameters for DRM Mode E ('DRM+') Concerning the Use in VHF Bands I, II and III, (V 3.0). 2011

[16] EUROPEAN BROADCASTING UNION. Case studies on the implementation of DRM+ in band II. EBU Technical Report 3357, Geneva, 2013

[17] ULOVEC, K.: Measurement of interactions between DRMplus and FM radio broadcasting systems in VHF band II. In Proc. of 25th International Conf. Radioelektronika. Pardubice (Czech Rep.), 2015, p. 369-372. DOI: 10.1109/RADIOELEK.2015.7129046

[18] INTERNATIONAL ELECTROTECHNICAL COMMISSION. Mobile and portable DVB-T/H radio access - Part 1: Interface specification. IEC Standard 62002-1, 2008 DOI: $10.3403 / 30185068$

[19] INTERNATIONAL ELECTROTECHNICAL COMMISSION. Methods of measurement on radio receivers for various classes of emission - Part 4: Receivers for frequency-modulated sound broadcasting emissions. IEC Standard 60315-4, 1998. DOI: $10.3403 / 01312783$

[20] FEILEN, M. DRM transmitter Spark. IMPRESSUM. Spark [Online] Cited 2015-06-13. Available at: http://www.drmsender.de/

[21] EUROPEAN CONFERENCE OF POSTAL AND TELECOMMUNICATIONS ADMINISTRATIONS. Method of measuring the maximum frequency deviation of FM broadcast emissions in the band 87.5 to $108 \mathrm{MHz}$ at monitoring stations. ERC Recommendation 54-01, 1998 (revised 2015)

[22] USRP1. ETTUS RESEARCH A NATIONAL INSTRUMENTS COMPANY. Ettus Research [Online] Cited 2015-06-13. Available at: http://www.ettus.com/product/details/USRPPKG

[23] MATTHES, A. SoDiRa Software Radio. Eingangsseite Bernd Reiser [Online] Cited 2015-06-13. Available at: http://www.dsp4swls.de/sodira/sodiraeng.html 


\section{About the Author ...}

Karel ULOVEC was born in Prague, Czech Republic in 1977. He received the M.S. and Ph.D. degrees in Electrical Engineering from the Faculty of Electrical Engineering, Czech Technical University in Prague (CTU), in 2001 and
2008 , respectively. Since 2004 , he is an assistant professor at the Department of Radio Engineering, Faculty of Electrical Engineering, Czech Technical University in Prague. His research interests are in areas of broadcasting systems and measurements of radio transmitters, receivers and systems. 